\title{
The Pricing of Options on Credit-Sensitive Bonds
}

\author{
Sandra Peterson ${ }^{1} \quad$ Richard C. Stapleton ${ }^{2}$
}

April 11, 2003

${ }^{1}$ Scottish Institute for Research in Investment and Finance, Strathclyde University, Glasgow, UK. Tel:(44)141-548-4958, e-mail:s.peterson@telinco.co.uk

${ }^{2}$ Department of Accounting and Finance, Strathclyde University, Glasgow, UK and University of Melbourne, Australia. Tel:(44)1524-381172, Fax:(44)524-846 874, e-mail:dj@staplet.demon.co.uk 


\section{Abstract The Pricing of Options on Credit-Sensitive Bonds}

We build a three-factor term-structure of interest rates model and use it to price corporate bonds. The first two factors allow the risk-free term structure to shift and tilt. The third factor generates a stochastic credit-risk premium. To implement the model, we apply the Peterson and Stapleton (2002) diffusion approximation methodology. The method approximates a correlated and lagged-dependent lognormal diffusion processes. We then price options on credit-sensitive bonds. The recombining log-binomial tree methodology allows the rapid computation of bond and option prices for binomial trees with up to forty periods. 


\section{Introduction}

The pricing of credit-sensitive bonds, that is, bonds which have a significant probability of default, is an issue of increasing academic and practical importance. The recent practice in financial markets has been to issue high yield corporate bonds that are a hybrid of equity and risk-free debt. Also, to an extent, most corporate bonds are credit-sensitive instruments, simply because of the limited liability of the issuing enterprise. In this paper, we suggest and implement a model for the pricing of options on credit-sensitive bonds. For example, the model can be used to price call provisions on bonds, options to issue bonds, and yield-spread options. From a modelling point of view, the problem is interesting because it involves at least three stochastic variables: at least two factors are required to capture shifts and tilts in the risk free short-term interest rate. The third factor is the credit spread, or default premium. In this paper we model the risk-free term structure using the Peterson, Stapleton, and Subrahmanyam (2002) [PSS] two-factor extension of the Black and Karasinski (1991) spot-rate model and add a correlated credit spread. To price the Bermudan- and Europeanstyle options efficiently, we need an approximation for the underlying diffusion processes for the risk-free rate, the term premium, and the credit spread. Here, we use the recombining binomial tree approach of Nelson and Ramaswamy (1990), extended to multiple variable diffusion processes by Ho, Stapleton and Subrahmanyam (1995)[HSS] and Peterson and Stapleton (2002).

There are two principal approaches to the modelling of credit-sensitive bond prices. Merton (1977)'s structural approach, recently re-examined by Longstaff and Schwartz (1995), prices corporate bonds as options, given the underlying stochastic process assumed for the value of the firm. On the other hand, the reduced form approach, used in recent work by Duffie and Singleton (1999) and Jarrow, Lando and Turnbull (1997), among others, assumes a stochastic process for the default event and an exogenous recovery rate. Our model is a reduced-form model that specifies the credit spread as an exogenous variable. Our approach follows the Duffie and Singleton "recovery of market value" (RMV) assumption. As Duffie and Singleton show, the assumption of a constant recovery rate on default, proportional to market value, justifies a constant period-by-period "risk-adjusted" discount rate. In our model, if there is no credit-spread volatility, we have the Duffie and Singleton RMV assumption as a special case.

A somewhat similar extension of the Duffie and Singleton approach to a stochastic credit spread has been suggested in Das and Sundaram (1999). They combine the credit-spread factor with a Heath, Jarrow and Morton (1992) type of forward-rate model for the dynamics of the risk-free rate. From a theoretical point of view, this approach is satisfactory, but 
it is difficult to implement for practical problems with multiple time intervals. Das and Sundaram only implement their model for an illustrative case of four time periods. In contrast, by using a recombining two-dimensional binomial lattice, we are able to efficiently compute bond and option prices for as many as forty time periods.

A possibly important influence on the price of credit-sensitive bonds is the correlation of the credit spread and the interest-rate process. To efficiently capture this dependence in a multiperiod model, we need to approximate a bivariate-diffusion process. Here, we assume that the interest rate and the credit spread are bivariate-lognormally distributed. In the binomial approximation, we use a modification and correction of the Ho-Stapleton-Subrahmanyam method, as suggested by Peterson and Stapleton (2002). The model provides a basis for more complex and realistic models, where yields on bonds could depend upon two interest rate factors plus a credit spread.

\section{Rationale of the Model}

We model the London Interbank Offer Rate $(L I B O R)$, as a lognormal diffusion process under the risk-neutral measure. Then, as in PSS, the second factor generating the term structure is the premium of the futures $L I B O R$ over the spot $L I B O R$. The second factor generating the premium is contemporaneously independent of the LIBOR. However, to guarantee that the no-arbitrage condition is satisfied, future outcomes of spot $L I B O R$ are related to the current futures $L I B O R$. This relationship creates a lag-dependency between spot LIBOR and the second factor. In addition, we assume that the one-period credit-adjusted discount rate, appropriate for discounting credit-sensitive bonds, is given by the product of the oneperiod $L I B O R$ and a correlated credit factor. We assume that since this credit factor is an adjustment to the short-term $L I B O R$, it is independent of the futures premium. This argument leads to the following set of equations. We let $\left(x_{t}, y_{t}, z_{t}\right)$ be a joint stochastic process for three variables representing the logarithm of the spot LIBOR, the logarithm of the futures-premium factor, and the logarithm of the credit premium factor. We have:

$$
\begin{aligned}
d x_{t} & =\mu(x, y, t) d t+\sigma_{x}(t) d W_{1, t} \\
d y_{t} & =\mu(y, t) d t+\sigma_{y}(t) d W_{2, t} \\
d z_{t} & =\mu(z, t) d t+\sigma_{z}(t) d W_{3, t}
\end{aligned}
$$

where $E\left(d W_{1, t} d W_{3, t}\right)=\rho, E\left(d W_{1, t} d W_{2, t}\right)=0, E\left(d W_{2, t} d W_{3, t}\right)=0$. 
Here, the drift of the $x_{t}$ variable, in equation (1), depends on the level of $x_{t}$ and also on the level of $y_{t}$, the futures premium variable. Clearly, if the current futures is above the spot, then we expect the spot to increase. Thus, the mean drift of $x_{t}$ allows us to reflect both mean reversion of the spot and the dependence of the future spot on the futures rate. The drift of the $y_{t}$ variable, in equation (2), also depends on the level of $y_{t}$, reflecting possible mean reversion in the futures premium factor. We note that equations (1) and (2) are identical to those in the two-factor risk-free bond model of Peterson, Stapleton and Subrahmanyam (2002). The additional equation, equation (3), allows us to model a meanreverting credit-risk factor. Also, the correlation between the innovations $d W_{1, t}$ and $d W_{3, t}$ enables us to reflect the possible correlation of the credit-risk premium and the short rate.

First, we assume, as in HSS, that $x_{t}, y_{t}$ and $z_{t}$ follow mean-reverting Ornstein-Uhlenbeck processes:

$$
\begin{aligned}
d x_{t} & =\kappa_{1}\left(a_{1}-x_{t}\right) d t+y_{t-1}+\sigma_{x}(t) d W_{1, t} \\
d y_{t} & =\kappa_{2}\left(a_{2}-y_{t}\right) d t+\sigma_{y}(t) d W_{2, t}, \\
d z_{t} & =\kappa_{3}\left(a_{3}-z_{t}\right) d t+\sigma_{z}(t) d W_{3, t},
\end{aligned}
$$

where $E\left(d W_{1, t} d W_{3, t}\right)=\rho d t, E\left(d W_{1, t} d W_{2, t}\right)=0, E\left(d W_{2, t} d W_{3, t}\right)=0$. and where the variables mean revert at rates $\kappa_{j}$ to $a_{j}$, for $j=x, y, z$.

As in Amin(1995), we rewrite these correlated processes in the orthogonalized form:

$$
\begin{aligned}
d x_{t} & =\kappa_{1}\left(a_{1}-x_{t}\right) d t+y_{t-1}+\sigma_{x}(t) d W_{1, t} \\
d y_{t} & =\kappa_{2}\left(a_{2}-y_{t}\right) d t+\sigma_{y}(t) d W_{2, t} \\
d z_{t} & =\kappa_{3}\left(a_{3}-z_{t}\right) d t+\rho \sigma_{z}(t) d W_{1, t}+\sqrt{1-\rho^{2}} \sigma_{z}(t) d W_{4, t}
\end{aligned}
$$

where $E\left(d W_{1, t} d W_{4, t}\right)=0$. Then, rearranging and substituting for $d W_{1, t}$ in (9), we can write

$$
d z_{t}=\kappa_{3}\left(a_{3}-z_{t}\right) d t-\beta_{x, z}\left[\kappa_{1}\left(a_{1}-x_{t}\right)\right] d t+\beta_{x, z} d x_{t}+\sqrt{1-\rho^{2}} \sigma_{z}(t) d W_{4, t} .
$$

In this trivariate system, $y_{t}$ is an independent variable and $x_{t}$ and $z_{t}$ are dependent variables. The discrete form of the system can be written as follows:

$$
x_{t}=\alpha_{x, t}+\beta_{x, t} x_{t-1}+y_{t-1}+\varepsilon_{x, t}
$$




$$
\begin{aligned}
& y_{t}=\alpha_{y, t}+\beta_{y, t} y_{t-1}+\varepsilon_{y, t} \\
& z_{t}=\alpha_{z, t}+\beta_{z, t} z_{t-1}+\gamma_{z, t} x_{t-1}+\delta_{z, t} x_{t}+\varepsilon_{z, t}
\end{aligned}
$$

where

$$
\begin{gathered}
\alpha_{x, t}=\kappa_{1} a_{1} h \\
\alpha_{y, t}=\kappa_{2} a_{2} h \\
\alpha_{z, t}=\left[\kappa_{3} a_{3}-\beta_{x, z} \kappa_{1} a_{1}\right] h \\
\beta_{x, t}=1-\kappa_{1} h \\
\beta_{y, t}=1-\kappa_{2} h \\
\beta_{z, t}=1-\kappa_{3} h \\
\gamma_{z, t}=\beta_{x, z}\left(-1+\kappa_{1} h\right) \\
\delta_{z, t}=-\beta_{x, z} \\
\beta_{x, z}=\frac{\rho \sigma_{z}(t)}{\sigma_{x}(t)}
\end{gathered}
$$

Equations (10)-(12) can be used to approximate the joint process in (4)-(6).

Proposition 1 (Approximation of a Three-Factor Diffusion Process) Suppose that $X_{t}, Y_{t}, Z_{t}$ follows a joint-lognormal process where the logarithms of $X_{t}, Y_{t}$ and $Z_{t}$ are given by

$$
\begin{aligned}
x_{t} & =\alpha_{x, y, t}+\beta_{x, t} x_{t-1}+y_{t-1}+\varepsilon_{x, t} \\
y_{t} & =\alpha_{y, t}+\beta_{y, t} y_{t-1}+\varepsilon_{y, t} \\
z_{t} & =\alpha_{z, t}+\beta_{z, t} z_{t-1}+\gamma_{z, t} x_{t-1}+\delta_{z, t} x_{t}+\varepsilon_{z, t}
\end{aligned}
$$

Let the conditional logarithmic standard deviation of $J_{t}$ be $\sigma_{j}(t)$ for $J=(X, Y, Z)$, where $J=u_{J}^{r} d_{J}^{N-r} E(J)$. If $J_{t}$ is approximated by a log-binomial distribution with binomial density $N_{t}=N_{t-1}+n_{t}$ and if the proportionate up and down movements, $u_{j_{t}}$ and $d_{j_{t}}$ are given by

$$
\begin{aligned}
& d_{j_{t}}=\frac{2}{1+\exp \left(2 \sigma_{j}(t) \sqrt{\tau_{t} / n_{t}}\right)} \\
& u_{j_{t}}=2-d_{j_{t}}
\end{aligned}
$$


and the conditional probability of an up-move at node $r$ of the lattice is given by

$$
q_{j_{t}}=\frac{E_{t-1}\left(j_{t}\right)-\left(N_{t-1}-r\right) \ln \left(u_{j_{t}}\right)-\left(n_{t}+r\right) \ln \left(d_{j_{t}}\right)}{n_{t}\left[\ln \left(u_{j_{t}}\right)-\ln \left(d_{j_{t}}\right)\right]}
$$

then the unconditional mean and volatility of the approximated process approach their true values, i.e., $\hat{E}_{0}\left(J_{t}\right) \rightarrow E_{0}\left(J_{t}\right)$ and $\hat{\sigma}_{j_{t}} \rightarrow \sigma_{j_{t}}$ as $n \rightarrow \infty$.

Proof The result follows as a special case of HSS (1995), Theorem $1^{1}$.

In essence, the binomial approximation methodology of HSS captures both the mean reversion and the correlation of the processes by adjusting the conditional probability of movements up and down in the trees. We choose the conditional probabilities to reflect the conditional mean of the process at a time and node. The proposition establishes that the binomial approximated process converges to the true multivariate lognormal diffusion process.

In contrast to Nelson and Ramaswamy, the HSS methodology on which our approximation is based relies on the lognormal property of the variables. The linear property of the joint normal (logarithmic) variables enables the conditional mean to be fixed easily, using the conditional probabilities. In contrast, the lattice methods discussed, for example, in Amin (1995), fix the mean reversion and correlation of the variables by choosing probabilities on a node-by-node basis. Also, as pointed out in Peterson and Stapleton (2002), the HSS method fixes the unconditional mean of the variables exactly, whearas the logarithmic mean converges to its true value as $n \rightarrow \infty$. If we apply the Nelson and Ramaswamy method to the case of lognormally distributed variables, the mean of the variable converges to its true value. However, we note that in all these methods the approximation improves as the number of binomial stages increases. Hence, the choice between the various methods of approximation is essentially one of convenience.

\section{The Price of a Credit-Sensitive Bond}

Our model is a reduced form model that specifies the credit spread as an exogenous variable and then discounts the bond market value on a period-by-period basis. This approach is consistent with the Duffie and Singleton recovery of market value (RMV) assumption.

\footnotetext{
${ }^{1}$ See Peterson and Stapleton (2002) for details on the implementation of the binomial approximation.
} 
Duffie and Singleton show that the assumption of a constant recovery rate on default, proportional to market value, justifies a constant period by period "risk-adjusted" discount rate. In our model, if the credit spread volatility goes to zero, we have the Duffie and Singleton RMV assumption as a special case. In our stochastic model, we assume that the price of a credit-sensitive, zero-coupon, $T$-maturity bond at time $t$ is given by the relation :

$$
B_{t, T}=E_{t}\left(B_{t+1, T}\right) \frac{1}{1+r_{t} \pi_{t} h}
$$

with the condition, $B_{T, T}=1$, in the event of no default prior to maturity. In (14), $E_{t}$ is the expectation operator, where expectations are taken with respect to the risk-neutral measure, $r_{t}$ is the risk-free, one-period rate of interest defined on a LIBOR basis, and $\pi_{t}>1$ is the credit spread factor. The time period length from, $t$ to $t+1$, is $h$. In this model, the value of a risk-free, zero-coupon bond is given by

$$
b_{t, T}=E_{t}\left(b_{t+1, T}\right) \frac{1}{1+r_{t} h}
$$

where $b_{T, T}=1$ and, for the risk-free bond, $\pi_{t}=1$. Equations (14) and (15) abstract from any consideration of the effects of risk aversion, whether to interest rate risk or default risk. We assume secondly, that the dynamics of the joint process of $r_{t}, \pi_{t}$ are governed by the stochastic differential equations

$$
\begin{aligned}
d \ln \left(r_{t}\right) & =\kappa_{1}\left[a_{1}-\ln \left(r_{t}\right)\right] d t+\ln \left(\phi_{t}\right)+\sigma_{r}(t) d W_{1, t} \\
d \ln \left(\phi_{t}\right) & =\kappa_{2}\left[a_{2}-\ln \left(\phi_{t}\right)\right] d t+\sigma_{\phi}(t) d W_{2, t} \\
d \ln \left(\pi_{t}\right) & =\kappa_{3}\left[a_{3}-\ln \left(\pi_{t}\right)\right] d t+\sigma_{\pi}(t) d W_{3, t}
\end{aligned}
$$

with $E\left(d W_{1, t} d W_{2, t}\right)=\rho$. We note that the system of equations is the same as equations (7)-(9), with the definitions $x_{t}=\ln \left(r_{t}\right), y_{t}=\ln \left(\phi_{t}\right)$, and $z_{t}=\ln \left(\pi_{t}\right)$. Hence, given (16)(18), the spot LIBOR, $r_{t}$, and the credit spread, $\pi_{t}$, follow correlated, lognormal diffusion processes. They can, Therefore, the processes can be approximated using the methodology described in Section 3. The stochastic model for the short-term risk-free rate follows the process in the PSS two-factor model. The short rate is lognormal and the logarithm of the rate follows a generalized Ornstein-Uhlenbeck process, under the risk-neutral measure. The process is generalized in the sense that the volatility, $\sigma_{r}(t)$, is time dependent. Hence, 
if required, the model for the risk-free rate can be calibrated to the prices of interest rate options observed in the market.

Recent research suggests that the credit spread is strongly mean reverting. ${ }^{2}$ Also, there is evidence that the credit spread and the short rate are weakly correlated. Finally, although inconclusive, the evidence of Chan et al (1992) suggests that lognormality of the short rate is a somewhat better assumption than the analytically more convenient assumption of the Vasicek and Hull-White model in which the short rate follows a Gaussian process. Hence, the model represented by equations (14), (16) and (18) has some empirical support.

One of the main problems that arises in constructing the model is calibrating the interest rate process (16) to the existing term structure of interest rates. This calibration is required to guarantee that the no-arbitrage condition is satisfied. In Black and Karasinski (1991), an iterative procedure is used, so that the prices in equation (15) match the given term structure. Here, we use the more direct approach of PSS, who use the fact that the futures $L I B O R$ is the expected value, under the risk-neutral measure, of the future spot LIBOR. This result in turn follows from Sundaresan (1991) and PSS, Lemma 1. Building the two-factor interest rate model (16) in this manner also guarantees that the no-arbitrage condition holds at each node, and at each future date.

To put the PSS method into effect, we take the discrete form of the short-rate process (16):

$$
\ln \left(r_{t}\right)=\ln \left(r_{t-1}\right)+\kappa_{1} a_{1} h-\kappa_{1} h \ln \left(r_{t-1}\right)+\ln \left(\phi_{t-1}\right)+\sigma_{r}(t) \sqrt{h} \varepsilon_{1, t}
$$

We then transform the process in (19) to have a unit mean by dividing by the futures LIBOR $f_{0 . t}$. This gives

$$
\ln \left(\frac{r_{t}}{f_{0, t}}\right)=\alpha_{r}+\left(1-\kappa_{1} h\right) \ln \left(\frac{r_{t-1}}{f_{0, t-1}}\right)+\ln \left(\phi_{t-1}\right)+\sigma_{r}(t) \sqrt{h} \varepsilon_{1, t}
$$

with

$$
\alpha_{r}=\kappa_{1} a_{1} h-\ln \left(f_{0, t}\right)+\left(1-\kappa_{1} h\right) \ln \left(f_{0, t-1}\right) .
$$

The process in (20) has unit mean, since $f_{0, t}=E\left(r_{t}\right)$, where the expectation is under the risk-neutral measure. As shown by Sundaresan (1991) and reiterated in PSS lemma 1, the

\footnotetext{
${ }^{2}$ See Tauren (1999)
} 
futures $L I B O R$ is traded as a price, and hence the Cox, Ingersoll and Ross (1981) expectation result holds for the LIBOR. Therefore, we build a model of the risk-free rate using the transformed process (20), and then calibrate the rates to the existing term structure of futures $L I B O R$ prices by multiplying by $f_{0, t}$, for all $t$.

The credit spread, $\pi_{t}$, is also assumed to follow a lognormal process. We assume as given the expected value of $\pi_{t}$, for all $t$, where $E\left(\pi_{t}\right)$ is the expectation under the risk-neutral measure. In principle, these expectations could be estimated by calibrating the model to the existing term structure of credit-sensitive bond prices. However, we assume that one of the purposes of the model is to price credit-sensitive bonds at $t=0$. Hence, these expected spreads are taken as exogenous. Taking the discrete form of (18), and transforming the process to a unit mean process, we have

$$
\ln \left(\frac{\pi_{t}}{E\left(\pi_{t}\right)}\right)=\alpha_{\pi}+\left(1-\kappa_{2} h\right) \ln \left(\frac{\pi_{t-1}}{E\left(\pi_{t-1}\right)}\right)+\sigma_{\pi}(t) \sqrt{h} \varepsilon_{2, t}
$$

with

$$
\alpha_{\pi}=\kappa_{2} a_{2} h-\ln \left[E\left(\pi_{t}\right)\right]+\left(1-\kappa_{2} h\right) \ln \left[E\left(\pi_{t-1}\right)\right]
$$

Assuming that the credit spread is lognormally distributed has advantages and disadvantages. One advantage is that the one-period credit-sensitive yield in the model $r_{t} \pi_{t}$ is also lognormal. This assumption provides consistency between the default-free and creditsensitive yield distributions. However, we must take care that data input do not lead to $\pi_{t}$ values of less than unity. In the implementation of the model, we truncate the distribution of $\pi_{t}$ as a lower limit of 1 .

\section{Illustrative Output of the Model}

In this section, we illustrate the model using a three-period example. Three periods are sufficient to show the structure of the model and the risk-free rates, risk-adjusted rates, and bond prices produced. For illustration, we assume a flat term structure of futures rates at $t=0$. Each futures rate is $2.69 \%$. We assume annual time intervals and flat caplet volatilities of $10 \%$ for 1-, 2-, and 3-year caplets. We assume that the spot LIBOR mean reverts at a rate of $30 \%$. The PSS model requires an estimate of the futures premium 
volatility and mean reversion. We assume a volatility of $2 \%$ and a mean reversion of $10 \%$. To implement the model, we require estimates of the credit risk premium and its volatility, mean reversion, and correlation with the $L I B O R$. In this example, we assume the current risk premium is $20 \%$, i.e., $\pi_{0}=1.2$, its volatility is $12 \%$, mean reversion $20 \%$ and its correlation with the short-term interest rate is $\rho=0.2$.

To illustrate the output, we restrict the model to have a binomial density of $n=1$ for each of the three variables. Therefore, the model, with $n=1$, produces eight possible zero-coupon risky-bond prices at time $t=1,27$ prices at time $t=2$, and in general $(t+1)^{3}$ prices at time $t$. Table 1 shows the outcome of the three variables in the model. $r_{t}$ is the risk-free $L I B O R$. $R_{t}$ is the risk-adjusted short-term rate. $y_{t}$ is the term premium of the futures rate over the $L I B O R$ and $\pi_{t}$ is the credit premium. Table 1 shows how the adapted PSS model recombines in three dimensions to produce a nonexploding tree of risk-adjusted interest rates. We note that there are two, three, and four different risk-free short rates at times 1, 2, and 3, respectively. However, there are four, nine, and 16 different risk-adjusted rates at those dates. Table 3 shows the bond price process for a four-period model, with the binomial density $t=1$. Table 2 shows the process for the risk-free bond price. Here, there are $(t+1)^{2}$ prices at time $t$. 


\section{Numerical Results: Bermudan Swaptions and Options on Coupon Bonds}

To price options on defaultable bonds, we calibrate the model to the futures strip and the cap volatility curve on the 18 July 2000, when the spot three-month LIBOR was approximately $7 \%$. This calibration exercise gives a volatility of three-month $L I B O R$ of $9.9 \%$ and a volatility of the first futures premium of $9.2 \%$. The mean reversion of these variables is $170 \%$ per annum and $13 \%$ per annum, respectively. The multiperiod model is simulated in three-month intervals to reflect the innovations in the three-month $L I B O R$ futures curve. PSS use data for the 18th of July 2000 for swaption calibration of their two- and three-factor interest rate models. (We refer the reader to that paper for details of the futures strip, cap volatility curve, and swaption prices on this date.) Both the expectations of the futures premium and the credit risk premium curve are equal to their current levels.

Table 4 shows European and Bermudan swaption prices for differing levels of moneyness and different levels of the credit-risk premium. The at-the-money level is assumed to be at a $7.5 \%$ strike. We price different swaptions using binomial densities of $n=1$ and $n=2$ and then use Richardson extrapolation to find the asymptotic price (denoted r/e in the tables). We assume that the volatility and mean reversion of the risk premium is $10 \%$ per annum and $20 \%$ per annum, respectively. The correlation between the short rate and the credit risk premium is $20 \%$. Columns $4-8$ show the prices of one-year options on one, two, three, four, and five year swaps, respectively. Column 9 shows the price of a Bermudan swaption that is exercisable annually for five years on a six-year underlying bond.

Tables 5 and 6 demonstrate the effect of varying the level and mean reversion of the creditrisk premium compared to the model prices reported in Table 4 . Table 5 shows the same calibrated model, but with a higher mean reversion of credit-risk premium of $50 \%$. Table 6 shows the calibrated model with higher volatility (20\%) and mean reversion of $50 \%$. All prices shown are in basis points.

Table 4 demonstrates that the spread between the price difference of a $1 / 5$ year payer swaption and its Bermudan counterpart reduces as the level of the credit-risk premium increases. Out-of-the-money spreads are reduced from $100 \%$ to $9 \%$, whereas in-the-money spreads reduce from $6 \%$ to under $1 \%$. Table 5 shows the effect of increasing the mean reversion over the model in Table 4. The spread between the Bermudan swaption and the one-year option on the five-year swap decreases for out-of-the-money, in-the-money, and atthe-money swaptions. The at-the-money swaptions have a $27 \%$ spread for a credit premium level of 1.1, whereas Table 4 shows a $30 \%$ spread for the same credit premium level. Other levels show a similiar decrease. Table 6 shows the effect of increasing the volatility of 
the credit premium. As expected, the spread between the European- and Bermudan-style options widens. However, in some cases the raw prices are reduced. For example, Table 6 shows an out-of-the-money $1 / 5$ swaption $\mathrm{r}$ /e price of 560 basis points, and its corresponding Bermudan of 605 basis points. Table 5 shows 582 and 617 basis points, respectively. This phenonemum is perhaps due to extrapolation error. In both the cases of a binomial density 2 and 3, the Table 6 swaption prices are higher than the corresponding Table 5 prices, i.e., 635 and 620 versus 605 and $611 .^{3}$

Tables 7 shows both European and Bermudan-style options on coupon bonds for differing levels of coupon-rate moneyness and credit-risk premium. Table 8 prices the same options, but with a volatile credit-risk premium, with volatility of $10 \%$, and mean reversion at $20 \%$ per annum. Both the models are calibrated to the same futures and caps as in the previous example. The correlation between the short rate and the credit-risk premium is $20 \%$. The models are simulated for 12 periods, with resets at three-month intervals. The European coupon-bond option is exercisable at year one on a four-year underlying bond. The Bermudan coupon-bond option is exercisable yearly for three years on a four-year coupon bond. The strike price of a unit bond is $\$ 1$. All prices shown are in basis points.

Tables 7 and 8 show the effect of adding risk to the credit premium on European- and Bermudan-style options on coupon bonds. When the option is struck at-the-money, the effect on the price can be to produce an increase of as much as $44 \%$. For example, when the credit premium level is at 1.4, the price of a Bermudan-style option increases from nine to 13 basis points. When the credit premium is lower at 1.1, the prices of the options struck deep in-the-money, increase by a much lesser amount. For example, the European-style 1-year option on the underlying four-year bond is priced at 250 basis points, and when risk is added to the premium, then the bond option is priced at 265 basis points, an increase of only $6 \%$.

\footnotetext{
${ }^{3}$ To correct such an extrapolation error, we could similate prices with the binomial density 4 or 5 and continue the extrapolation from these figures.
} 


\section{Conclusions}

We have proposed and implemented a three-factor model for the pricing of options on creditsensitive bonds. The first two factors represent movements in the risk-free interest rate, as in the two-factor version of the multifactor model of Peterson, Stapleton and Subrahmanyam (2002). The third factor is a credit spread factor that is correlated with the short-term interest rate. The model of the bond price process produces $(t+1)^{3}$ risky bond prices after $t$ periods. The computational efficiency of the model is achieved by using the recombining methodology outlined in Peterson and Stapleton (2002). This methodology allows us to capture the covariance of the credit spread and the $L I B O R$, as well as the two-factor riskfree rate process. European- and Bermudan-style options on bonds and on defaultable swaps are priced using the three-factor process. The results illustrate the sensitivity of these instruments to the level and volatility of the credit-risk premium.

Although we have been able to price options on defaultable coupon bonds for realistic cases, the three-factor model is obviously more computationally expensive than a twofactor model with a risk-free rate and a credit spread. The question arises as to whether the computational effort is wothwhile. The issue comes down to how volatile is the futures premium factor, and how long is the maturity of the coupon bonds. Evidence from PSS suggests that the volatility of the futures premium factor is high and has a significant effect on the pricing of swaptions. A similar conclusion is likely to hold for defaultable couponbond options. It follows that the three-factor model analysed in this article is a significant improvement on any simpler two-factor implementation. 
Model for Pricing Options on Credit-Sensitive Bonds

\section{References}

[1] Amin, K. I. (1991), "On the computation of continuous time option prices using discrete approximations", Journal of Financial and Quantitative Analysis, 26(4), pp. 447-495.

[2] Amin, K. I. (1995), "Option Pricing Trees", Journal of Derivatives, Summer edition, pp 34-46.

[3] Amin, K.I. and J.N. Bodrutha (1995), "Discrete-Time American Option Valuation with Stochastic Interest Rates," Review of Financial Studies, 8, pp.193-234.

[4] Black, F. and P. Karasinski (1991), "Bond and Option Pricing when Short Rates are Lognormal", Financial Analysts Journal, 47, pp. 52-59

[5] Chan, K., A. Karolyi, F. Longstaff and A. Saunders (1992), "An Empirical Comparison of Alternative Models of the Short Term Interest Rate", Journal of Finance, 47(3), pp1209-27.

[6] Chung, S-L. (1998), "Generalised Geske-Johnson Technique for the Valuation of American Options with Stochastic Interest Rates", Ph.D. Thesis, Lancaster University.

[7] Cox, J.C., J.E. Ingersoll, and S.A. Ross (1981), "The Relationship between Forward Prices and Futures Prices", Journal of Financial Economics, 9, pp. 321-346.

[8] Das, S. and R. Sundaram (1999), "A Discrete Time Approach to Arbitrage-Free Pricing of Credit Derivatives", working paper, NYU.

[9] Duffie, D. and K.J. Singleton, (1999), "Modeling Term Structures of Defaultable Bonds", Review of Financial Studies, 12(4), pp.687-720.

[10] Hilliard, J.E., and A. Schwartz, (1996), "Binomial Option Pricing Under Stochastic Volatility and Correlated State Variables", Journal of Derivatives, Fall, pp 55-75.

[11] Ho, T.S., R.C. Stapleton, and M.G. Subrahmanyam (1995), "Multivariate Binomial Approximations for Asset Prices with Non-Stationary Variance and Covariance Characteristics", Review of Financial Studies, 8(4), pp.1125-1152.

[12] Jarrow, R., D. Lando, and S. Turnbull (1997), "A Markov Model for the Term Structure of Credit Spreads", Review of Financial Studies, 10, pp. 481-523.

[13] Longstaff, F., and E. Schwartz (1995), "A simple Approach to Valuing Risky Fixed and Floating Rate Debt", Journal of Finance, 50, pp 789-820. 
[14] Merton, R.C., (1977), "On the Pricing of Contingent Claims and the Modigliani-Miller Theorem," Journal of Financial Economics, 5, pp 241-9

[15] Nelson, D.B. and K. Ramaswamy (1990), "Simple Binomial Processes as Diffusion Approximations in Financial Models", Review of Financial Studies, 3, pp. 393-430.

[16] Peterson, S.J. (1999), "The Application of Binomial Trees to Calculate Complex Option Prices, Two-factor Stochastic Interest Rate Option Prices and Value-at-Risk", Ph.D Thesis, Lancaster University.

[17] Peterson, S.J., R.C. Stapleton, and M.G. Subrahmanyam (2002), "The Valuation of Bermudan-Style Swaptions in a Multi-Factor Spot-Rate Model", forthcoming, Journal of Financial and Quantitative Analysis.

[18] Peterson, S.J. and R.C. Stapleton, (2002), "The Valuation of Bermudan-Style Options on Correlated Assets", Review of Derivatives Research, 5, pp. 127-151.

[19] Sundaresan, S. (1991), "Futures prices on Yields, Forward Prices, and Implied Forward Prices from Term Structure", Journal of Financial and Quantitative Analysis, 26, pp. 409-424.

[20] Tauren, M. (1999), "A Comparison of Bond Pricing Models in the Pricing of Credit Risk", presented at European Financial Association conference, Helsinki. 
Model for Pricing Options on Credit-Sensitive Bonds

Table 1: $L I B O R$, Term-Premium, Credit-Premium and Risk-Adjusted Yields

\begin{tabular}{|c|c|c|c|c|c|c|c|c|c|c|c|}
\hline row & $r_{1}$ & $\pi_{1}$ & $R_{1}$ & $\phi_{1}$ & $r_{2}$ & $\overline{\pi_{2}}$ & $R_{2}$ & $\phi_{2}$ & $r_{3}$ & $\overline{\pi_{3}}$ & $R_{3}$ \\
\hline 1 & & & & & & & & & 0.040 & 1.534 & 0.061 \\
\hline 2 & & & & & & & & & 0.040 & 1.212 & 0.048 \\
\hline 3 & & & & & & & & & 0.040 & 0.958 & 0.038 \\
\hline 4 & & & & & & & & & 0.040 & 0.757 & 0.030 \\
\hline 5 & & & & & 0.034 & 1.373 & 0.046 & 1.040 & & & \\
\hline 6 & & & & & 0.034 & 1.085 & 0.037 & 1.000 & 0.030 & 1.534 & 0.046 \\
\hline 7 & 0.030 & 1.229 & 0.036 & 1.020 & 0.034 & 0.857 & 0.029 & 0.960 & 0.030 & 1.212 & 0.036 \\
\hline 8 & 0.030 & 0.971 & 0.029 & 0.980 & & & & & 0.030 & 0.958 & 0.029 \\
\hline 9 & & & & & 0.027 & 1.373 & 0.036 & 1.040 & 0.030 & 0.757 & 0.023 \\
\hline 10 & & & & & 0.027 & 1.085 & 0.029 & 1.000 & & & \\
\hline 11 & & & & & 0.027 & 0.857 & 0.023 & 0.960 & 0.023 & 1.534 & 0.035 \\
\hline 12 & 0.024 & 1.229 & 0.030 & 1.020 & & & & & 0.023 & 1.212 & 0.028 \\
\hline 13 & 0.024 & 0.971 & 0.024 & 0.980 & 0.021 & 1.373 & 0.029 & 1.040 & 0.023 & 0.958 & 0.022 \\
\hline 14 & & & & & 0.021 & 1.085 & 0.023 & 1.000 & 0.023 & 0.757 & 0.017 \\
\hline 15 & & & & & 0.021 & 0.857 & 0.018 & 0.960 & & & \\
\hline 16 & & & & & & & & & 0.017 & 1.534 & 0.027 \\
\hline 17 & & & & & & & & & 0.017 & 1.212 & 0.021 \\
\hline 18 & & & & & & & & & 0.017 & 0.958 & 0.017 \\
\hline 19 & & & & & & & & & 0.017 & 0.757 & 0.013 \\
\hline
\end{tabular}

This table shows the outcome of the three primary variables: LIBOR $\left(r_{t}\right)$, the credit spread factor $\left(\pi_{t}\right)$, and the futures-premium factor $\left(\phi_{t}\right)$.In addition, the table shows the risk-adjusted one-period yield $\left(R_{t}\right)$. There are $t+1$ outcomes of each variable after $t$ periods in the multidimensional recombining tree. 


\section{Table 2: The Price Process for a 4-Year Risk-Free Bond}

\begin{tabular}{cccccccc}
\hline row & $b_{0,4}$ & $b_{1,4}$ & $b_{1,4}$ & $b_{2,4}$ & $b_{2,4}$ & $b_{2,4}$ & $b_{3,4}$ \\
\hline 1 & & & & & & & 0.9615 \\
2 & & & & 0.9383 & 0.9383 & 0.9349 & \\
3 & & 0.9190 & 0.9208 & & & & 0.9705 \\
4 & 0.8988 & & & 0.9518 & 0.9518 & 0.9518 & \\
5 & & 0.9307 & 0.9327 & & & & 0.9774 \\
6 & & & & 0.9591 & 0.9625 & 0.9625 & \\
7 & & & & & & & 0.9828
\end{tabular}

The first column shows the price of the zero-coupon, risk-free bond at $t=0$. The second and third columns show the price of the bond at $t=1$, where the futures premium factors are high and low, respectively. Rows 2 and 3 show the bond prices when the LIBOR is high. Columns 4-6 show the bond prices at $t=2$, when the futures premium factors are high, medium, and low, respectively. Row 1 shows the bond price at $t=3$ when $L I B O R$ is in the top state. Row 7 shows it in the bottom state. 
Model for Pricing Options on Credit-Sensitive Bonds

Table 3: The Price Process for a 4-Year Risky Bond

\begin{tabular}{|c|c|c|c|c|c|c|c|}
\hline row & $B_{0,4}$ & $B_{1,4}$ & $B_{1,4}$ & $B_{2,4}$ & $B_{2,4}$ & $B_{2,4}$ & $B_{3,4}$ \\
\hline 1 & & & & & & & 0.9421 \\
\hline 2 & & & & & & & 0.9537 \\
\hline 3 & & & & & & & 0.9630 \\
\hline 4 & & & & & & & 0.9706 \\
\hline 5 & & & & 0.9147 & 0.9166 & 0.9185 & \\
\hline 6 & & & & 0.9302 & 0.9318 & 0.9334 & 0.9554 \\
\hline 7 & & & & 0.9429 & 0.9443 & 0.9456 & 0.9644 \\
\hline 8 & & 0.8994 & 0.9032 & & & & 0.9717 \\
\hline 9 & & 0.9159 & 0.9192 & 0.9298 & 0.9313 & 0.9327 & 0.9775 \\
\hline 10 & 0.8885 & & & 0.9426 & 0.9438 & 0.9451 & \\
\hline 11 & & 0.9124 & 0.9156 & 0.9531 & 0.9542 & 0.9552 & 0.9658 \\
\hline 12 & & 0.9268 & 0.9296 & & & & 0.9728 \\
\hline 13 & & & & 0.9431 & 0.9438 & 0.9449 & 0.9784 \\
\hline 14 & & & & 0.9536 & 0.9541 & 0.9550 & 0.9828 \\
\hline 15 & & & & 0.9621 & 0.9626 & 0.9634 & \\
\hline 16 & & & & & & & 0.9738 \\
\hline 17 & & & & & & & 0.9792 \\
\hline 18 & & & & & & & 0.9835 \\
\hline 19 & & & & & & & 0.9869 \\
\hline
\end{tabular}

The first column shows the price of the zero-coupon, credit-risky bond at $t=0$. The second and third colums show the price of the bond at $t=1$, where the futures premium factors are high and low, respectively. Rows 8 and 9 show the bond prices when the LIBOR is high, and the credit premiums are high and low, respectively. Columns $4-6$ show the bond prices at $t=2$, when the futures premium factors are high, medium, and low, respectively. Rows 5-7 show the bond prices when the $L I B O R$ is high and the credit premium factors are high, medium, and low, respectively. Rows 1-4 show the bond price at $t=3$ when $L I B O R$ is in the top state and the credit premim is at different levels. 
Table 4: Swaptions: Low risk premium volatility and low mean reversion

\begin{tabular}{|c|c|c|c|c|c|c|c|c|}
\hline strike & Premium Level & $n$ & $1 / 1$ & $1 / 2$ & $1 / 3$ & $1 / 4$ & $1 / 5$ & Bermudan \\
\hline \multirow[t]{9}{*}{$6.5 \%$} & \multirow[t]{3}{*}{1.1} & 2 & 135 & 261 & 378 & 487 & 589 & 626 \\
\hline & & 3 & 134 & 258 & 372 & 479 & 579 & 615 \\
\hline & & $\mathrm{r} / \mathrm{e}$ & 132 & 255 & 366 & 470 & 569 & 604 \\
\hline & \multirow[t]{3}{*}{1.2} & 2 & 192 & 369 & 531 & 682 & 823 & 842 \\
\hline & & 3 & 191 & 365 & 525 & 675 & 814 & 832 \\
\hline & & $\mathrm{r} / \mathrm{e}$ & 190 & 362 & 520 & 667 & 806 & 822 \\
\hline & \multirow[t]{3}{*}{1.4} & 2 & 310 & 588 & 839 & 1070 & 1282 & 1284 \\
\hline & & 3 & 308 & 584 & 834 & 1063 & 1273 & 1275 \\
\hline & & $\mathrm{r} / \mathrm{e}$ & 306 & 580 & 829 & 1056 & 1264 & 1266 \\
\hline \multirow[t]{9}{*}{$7.5 \%$} & \multirow[t]{3}{*}{1.1} & 2 & 70 & 139 & 200 & 256 & 306 & 382 \\
\hline & & 3 & 69 & 135 & 193 & 245 & 292 & 372 \\
\hline & & $\mathrm{r} / \mathrm{e}$ & 67 & 130 & 186 & 234 & 278 & 361 \\
\hline & \multirow[t]{3}{*}{1.2} & 2 & 116 & 226 & 325 & 415 & 499 & 554 \\
\hline & & 3 & 115 & 222 & 318 & 405 & 486 & 542 \\
\hline & & $\mathrm{r} / \mathrm{e}$ & 114 & 217 & 310 & 396 & 473 & 531 \\
\hline & \multirow[t]{3}{*}{1.4} & 2 & 226 & 429 & 613 & 781 & 935 & 953 \\
\hline & & 3 & 224 & 426 & 607 & 773 & 926 & 943 \\
\hline & & $\mathrm{r} / \mathrm{e}$ & 223 & 422 & 601 & 765 & 916 & 933 \\
\hline \multirow[t]{9}{*}{$8.5 \%$} & \multirow[t]{3}{*}{1.1} & 2 & 30 & 61 & 88 & 111 & 129 & 225 \\
\hline & & 3 & 28 & 58 & 82 & 102 & 117 & 217 \\
\hline & & $\mathrm{r} / \mathrm{e}$ & 27 & 55 & 76 & 92 & 105 & 209 \\
\hline & \multirow[t]{3}{*}{1.2} & 2 & 60 & 119 & 172 & 217 & 256 & 346 \\
\hline & & 3 & 58 & 115 & 164 & 206 & 242 & 336 \\
\hline & & $\mathrm{r} / \mathrm{e}$ & 57 & 111 & 156 & 194 & 227 & 325 \\
\hline & \multirow[t]{3}{*}{1.4} & 2 & 150 & 286 & 408 & 518 & 618 & 669 \\
\hline & & 3 & 148 & 282 & 401 & 508 & 605 & 657 \\
\hline & & $\mathrm{r} / \mathrm{e}$ & 145 & 278 & 394 & 498 & 592 & 644 \\
\hline
\end{tabular}


The table shows swaption prices for in-the-money (6.5\%), at-the-money (7.5\%), and out-of-themoney (8.5\%) swaptions. Column 1 shows the strike rate of the swaption. Column 2 shows the spot level of the risk premium. The asymptotic price (r/e) is extrapolated from binomial densities ,$n=1$ and $n=2$ using Richardson extrapolation. The model is calibrated to the futures strip and the cap volatility curve on 18 July 2000 . From this calibration, we have the volatility of the three-month $L I B O R$ of $9.9 \%$ and the volatility of the first futures premium of $9.2 \%$, with mean reversions of $170 \%$ and $13 \%$, respectively. The correlation between the short rate and the credit-risk premium is assumed to be $20 \%$. The expected credit-risk premium curve is flat and equal to its spot. The volatility and mean reversion of the risk premiums are $10 \%$ per annum and $20 \%$, respectively. Columns 4-8 show the one year option on one-, two-, theree-, four-, and five-year swaps, respectively. Column 9 shows the price of a Bermudan swaption that is exercisable annually for five years on a six-year underlying swap. All prices are in basis points. 
Table 5: Swaptions: Low risk premium volatility and high mean reversion

\begin{tabular}{|c|c|c|c|c|c|c|c|c|}
\hline strike & Premium Level & $n$ & $1 / 1$ & $1 / 2$ & $1 / 3$ & $1 / 4$ & $1 / 5$ & Bermudan \\
\hline \multirow[t]{9}{*}{$6.5 \%$} & \multirow[t]{3}{*}{1.1} & 2 & 131 & 253 & 367 & 474 & 575 & 605 \\
\hline & & 3 & 133 & 256 & 370 & 477 & 579 & 611 \\
\hline & & $\mathrm{r} / \mathrm{e}$ & 134 & 259 & 373 & 481 & 582 & 617 \\
\hline & \multirow[t]{3}{*}{1.2} & 2 & 190 & 363 & 523 & 673 & 814 & 827 \\
\hline & & 3 & 191 & 365 & 525 & 676 & 817 & 832 \\
\hline & & $\mathrm{r} / \mathrm{e}$ & 192 & 367 & 528 & 679 & 821 & 836 \\
\hline & \multirow[t]{3}{*}{1.4} & 2 & 309 & 587 & 839 & 1071 & 1284 & 1285 \\
\hline & & 3 & 308 & 585 & 836 & 1066 & 1279 & 1280 \\
\hline & & $\mathrm{r} / \mathrm{e}$ & 307 & 582 & 832 & 1062 & 1274 & 1275 \\
\hline \multirow[t]{9}{*}{$7.5 \%$} & \multirow[t]{3}{*}{1.1} & 2 & 65 & 127 & 184 & 236 & 283 & 355 \\
\hline & & 3 & 67 & 131 & 188 & 239 & 286 & 362 \\
\hline & & $\mathrm{r} / \mathrm{e}$ & 69 & 134 & 191 & 243 & 290 & 369 \\
\hline & \multirow[t]{3}{*}{1.2} & 2 & 112 & 215 & 310 & 398 & 480 & 529 \\
\hline & & 3 & 113 & 219 & 314 & 402 & 484 & 535 \\
\hline & & $\mathrm{r} / \mathrm{e}$ & 115 & 222 & 318 & 406 & 488 & 542 \\
\hline & \multirow[t]{3}{*}{1.4} & 2 & 225 & 427 & 611 & 779 & 935 & 949 \\
\hline & & 3 & 224 & 425 & 607 & 775 & 930 & 944 \\
\hline & & $\mathrm{r} / \mathrm{e}$ & 223 & 423 & 604 & 771 & 925 & 938 \\
\hline \multirow[t]{9}{*}{$8.5 \%$} & \multirow[t]{3}{*}{1.1} & 2 & 24 & 51 & 73 & 92 & 107 & 199 \\
\hline & & 3 & 26 & 54 & 76 & 95 & 109 & 206 \\
\hline & & $\mathrm{r} / \mathrm{e}$ & 28 & 57 & 80 & 97 & 112 & 212 \\
\hline & \multirow[t]{3}{*}{1.2} & 2 & 54 & 107 & 154 & 194 & 230 & 317 \\
\hline & & 3 & 56 & 111 & 158 & 199 & 234 & 324 \\
\hline & & $\mathrm{r} / \mathrm{e}$ & 58 & 114 & 162 & 203 & 238 & 332 \\
\hline & \multirow[t]{3}{*}{1.4} & 2 & 148 & 282 & 402 & 512 & 612 & 657 \\
\hline & & 3 & 146 & 279 & 398 & 506 & 605 & 651 \\
\hline & & $\mathrm{r} / \mathrm{e}$ & 145 & 277 & 394 & 500 & 597 & 645 \\
\hline
\end{tabular}


The table shows swaption prices for in-the-money (6.5\%), at-the-money (7.5\%), and out-of-themoney $(8.5 \%)$ swaptions. Column 1 shows the strike rate of the swaption. Column 2 shows the spot level of the risk premium. The asymptotic price (r/e) is extrapolated from binomial densities,$n=1$ and $n=2$ using Richardson extrapolation. The model is calibrated to the futures strip and the cap volatility curve on 18 July 2000. From this calibration, we have the volatility of three-month LIBOR of $9.9 \%$ and the volatility of the first futures premium of $9.2 \%$, with mean reversion of $170 \%$ and $13 \%$, respectively. The correlation between the short rate and the credit risk premium is assumed to be $20 \%$. The expected credit-risk premium curve is flat and equal to its spot. The volatility and mean reversion of the risk premium are $10 \%$ per annum and 50\%, respectively. Columns $4-8$ show the one-year option on one-, two-, three-, four-, and five-year swaps, respectively. Column 9 shows the price of a Bermudan swaption that is exercisable annually for five years on a six-year underlying swap. All prices are in basis points. 
Table 6: Swaptions: High risk premium volatility and high mean reversion

\begin{tabular}{|c|c|c|c|c|c|c|c|c|}
\hline strike & Premium Level & $n$ & $1 / 1$ & $1 / 2$ & $1 / 3$ & $1 / 4$ & $1 / 5$ & Bermudan \\
\hline \multirow[t]{9}{*}{$6.5 \%$} & \multirow[t]{3}{*}{1.1} & 2 & 141 & 267 & 382 & 488 & 588 & 635 \\
\hline & & 3 & 137 & 260 & 372 & 476 & 574 & 620 \\
\hline & & $\mathrm{r} / \mathrm{e}$ & 134 & 253 & 362 & 464 & 560 & 605 \\
\hline & \multirow[t]{3}{*}{1.2} & 2 & 191 & 363 & 520 & 667 & 805 & 827 \\
\hline & & 3 & 192 & 365 & 523 & 670 & 808 & 832 \\
\hline & & $\mathrm{r} / \mathrm{e}$ & 194 & 367 & 526 & 673 & 812 & 838 \\
\hline & \multirow[t]{3}{*}{1.4} & 2 & 310 & 587 & 837 & 1066 & 1277 & 1282 \\
\hline & & 3 & 307 & 581 & 829 & 1056 & 1265 & 1269 \\
\hline & & $\mathrm{r} / \mathrm{e}$ & 304 & 575 & 820 & 1046 & 1253 & 1256 \\
\hline \multirow[t]{9}{*}{$7.5 \%$} & \multirow[t]{3}{*}{1.1} & 2 & 79 & 148 & 208 & 261 & 308 & 396 \\
\hline & & 3 & 76 & 141 & 196 & 245 & 290 & 381 \\
\hline & & $\mathrm{r} / \mathrm{e}$ & 73 & 134 & 185 & 230 & 271 & 366 \\
\hline & \multirow[t]{3}{*}{1.2} & 2 & 119 & 222 & 315 & 399 & 478 & 542 \\
\hline & & 3 & 120 & 226 & 319 & 403 & 482 & 549 \\
\hline & & $\mathrm{r} / \mathrm{e}$ & 122 & 229 & 323 & 408 & 485 & 556 \\
\hline & \multirow[t]{3}{*}{1.4} & 2 & 229 & 432 & 613 & 779 & 931 & 957 \\
\hline & & 3 & 225 & 425 & 603 & 767 & 918 & 942 \\
\hline & & $\mathrm{r} / \mathrm{e}$ & 222 & 417 & 594 & 755 & 905 & 927 \\
\hline \multirow[t]{9}{*}{$8.5 \%$} & \multirow[t]{3}{*}{1.1} & 2 & 39 & 72 & 97 & 117 & 133 & 239 \\
\hline & & 3 & 36 & 65 & 87 & 104 & 117 & 227 \\
\hline & & $\mathrm{r} / \mathrm{e}$ & 34 & 59 & 77 & 91 & 101 & 214 \\
\hline & \multirow[t]{3}{*}{1.2} & 2 & 65 & 119 & 164 & 203 & 236 & 338 \\
\hline & & 3 & 67 & 122 & 168 & 207 & 240 & 346 \\
\hline & & $\mathrm{r} / \mathrm{e}$ & 69 & 126 & 172 & 211 & 244 & 353 \\
\hline & \multirow[t]{3}{*}{1.4} & 2 & 157 & 293 & 412 & 520 & 616 & 680 \\
\hline & & 3 & 153 & 285 & 401 & 504 & 599 & 663 \\
\hline & & $\mathrm{r} / \mathrm{e}$ & 149 & 277 & 389 & 489 & 582 & 645 \\
\hline
\end{tabular}


The table shows swaption prices for in-the-money (6.5\%), at-the-money (7.5\%), and out-of-themoney $(8.5 \%)$ swaptions. Column 1 shows the strike rate of the swaption. Column 2 shows the spot level of the risk premium. The asymptotic price (r/e) is extrapolated from binomial densities,$n=1$ and $n=2$ using Richardson extrapolation. The model is calibrated to the futures strip and the cap volatility curve on 18 July 2000 . From this calibration, we have the volatility of three -month LIBOR of $9.9 \%$ and the volatility of the first futures premium of $9.2 \%$, with mean reversion of $170 \%$ and $13 \%$, respectively. The correlation between the short rate and the credit risk premium is assumed to be $20 \%$. The expected credit-risk premium curve is flat and equal to its spot. The volatility and mean reversion of the risk premium are $20 \%$ per annum and 50\%, respectively. Columns $4-8$ show the one year option on one-, two-, three-, four-, and five-year swaps, respectively. Column 9 shows the price of a Bermudan swaption that is exercisable annually for five years on a six-year underlying swap. All prices are in basis points. 
Model for Pricing Options on Credit-Sensitive Bonds

\section{Table 7: European and Bermudan Options on Coupon Bonds: Risk-Free Credit Premium}

\begin{tabular}{llllllll}
\hline Coupon Rate & $n$ & & Premium & \multicolumn{3}{l}{ Level } & \\
& & 1.1 & & 1.2 & & 1.4 & \\
\hline \multirow{2}{*}{$7 \%$} & & $1 / 3$ & Bermudan & $1 / 3$ & Bermudan & $1 / 3$ & Bermudan \\
& 2 & 23 & 47 & 6 & 24 & 0 & 6 \\
& 3 & 26 & 51 & 8 & 27 & 0 & 7 \\
& r/e & 29 & 54 & 10 & 29 & 0 & 9 \\
$8 \%$ & & & & & & & \\
& 2 & 101 & 129 & 44 & 72 & 4 & 22 \\
& 3 & 103 & 133 & 46 & 76 & 6 & 24 \\
& r/e & 106 & 136 & 48 & 80 & 8 & 27 \\
& & & & & & & \\
& 2 & 248 & 268 & 138 & 167 & 30 & 59 \\
& 3 & 249 & 271 & 141 & 171 & 34 & 63 \\
& r/e & 250 & 274 & 144 & 175 & 38 & 67 \\
\hline
\end{tabular}

The table shows prices for options on coupon bonds, for the coupon strike rates of $7 \%, 8 \%$, and $9 \%$. The asymptotic price ( $\mathrm{r} / \mathrm{e})$ is extrapolated from binomial densities $n=1$ and $n=2$. The model is calibrated to the futures strip and the cap volatility curve on 18 July 2000 . The volatility of three-month LIBOR of $9.9 \%$ and the volatility of the first futures premium of $9.2 \%$, with mean reversion of $170 \%$ and $13 \%$ respectively. The correlation between the short rate and the credit risk premium is $20 \%$. The futures credit risk premium curve is flat and equal to its spot. There is no volatility OR?? or mean reversion of the risk premium. The strike rate for a unit bond is $\$ 1$. All prices shown are in basis points. Columns 3, 5, and 7 show the one-year option on a four-year underlying bond for initial credit risk premium levels of 1.1, 1.2, and 1.4, respectively. Columns 4, 5 , and 7 show the price of a Bermudan-style swaption that is exercisable annually for three years on the same four-year underlying bond. 
Model for Pricing Options on Credit-Sensitive Bonds

Table 8: European and Bermudan Options on Coupon Bonds: Risky Credit
Premium

\begin{tabular}{cllllllll}
\hline Coupon Rate & $n$ & & Premium & \multicolumn{3}{l}{ Level } \\
& & 1.1 & & 1.2 & & 1.4 & \\
\hline \multirow{2}{*}{$7 \%$} & & $1 / 3$ & Bermudan & $1 / 3$ & Bermudan & $1 / 3$ & Bermudan \\
& 2 & 32 & 60 & 11 & 33 & 1 & 10 \\
& 3 & 34 & 63 & 12 & 35 & 1 & 11 \\
& $\mathrm{r} / \mathrm{e}$ & 35 & 66 & 14 & 38 & 1 & 13 \\
$8 \%$ & & & & & & & \\
& 2 & 115 & 146 & 56 & 87 & 9 & 31 \\
& 3 & 117 & 150 & 57 & 91 & 10 & 33 \\
& $\mathrm{r} / \mathrm{e}$ & 119 & 153 & 59 & 95 & 11 & 36 \\
& & & & & & & \\
& 2 & 262 & 286 & 155 & 186 & 41 & 74 \\
& 3 & 263 & 289 & 157 & 190 & 43 & 78 \\
& $\mathrm{r} / \mathrm{e}$ & 265 & 291 & 159 & 194 & 45 & 82 \\
\hline
\end{tabular}

The table shows prices for options on coupon bonds, for the coupon strike rates of $7 \%, 8 \%$, and $9 \%$. The asymptotic price ( $\mathrm{r} / \mathrm{e})$ is extrapolated from binomial densities $n=1$ and $n=2$. The model is calibrated to the futures strip and the cap volatility curve on 18 July 2000 . The volatility of three-month $L I B O R$ is $9.9 \%$ and the volatility of the first futures premium is $9.2 \%$, with mean reversion of $170 \%$ and $13 \%$, respectively. The correlation between the short rate and the credit risk premium is $20 \%$. The expected credit risk premium curve is flat and equal to its spot. The volatility and mean reversion of the risk premium is $20 \%$ per annum and $50 \%$, respectively. The strike rate of a unit bond is $\$ 1$. All prices shown are in basis points. Columns 3,5 , and 7 show the one-year option on a four-year underlying bond for initial credit risk premium levels of 1.1, 1.2 and 1.4 respectively. Columns 4,5 , and 7 show the price of a Bermudan-style swaption which is exercisable annually for three years on the same four-year underlying bond. 